\title{
Testing the Traditional CCAPM in the US: A Revisit
}

\author{
Chikashi Tsuji, Professor \\ Faculty of Economics, Chuo University \\ 742-1 Higashinakano Hachioji-shi, Tokyo 192-0393, Japan \\ E-mail: mail_sec_low@minos.ocn.ne.jp
}

Received: March 11, 2016 Accepted: April 1, 2016 Published: June 11, 2016

doi:10.5296/iss.v4i1.9586 URL: http//dx.doi.org/10.5296/iss.v4i1.9586

\begin{abstract}
This study re-examines the traditional consumption-based capital asset pricing model (CCAPM) by largely updating US monthly samples of consumption and stock market return and following the methodology of generalized method of moments (GMM) with instrumental variables of Hansen and Singleton (1982). As a result, our investigations reveal the following facts for the US stock market. First, 1) in the cases of the CCAPM with consumption for nondurable goods and the CCAPM with consumption for nondurable goods and services, their discount rate parameters almost always take similar values that are slightly less than one. Next, 2) their risk aversion parameters more stably take small minus values in the CCAPM with consumption for nondurable goods than in the CCAPM with consumption for nondurable goods and services. Third, 3) in our empirical examinations, all estimated CCAPMs with two kinds of consumption are not rejected by the $J$-tests.
\end{abstract}

Keywords: asset pricing, CCAPM, GMM 


\section{Introduction}

Asset pricing research by using the generalized method of moments (GMM) methodology (Hansen, 1982; Hansen and Singleton, 1982) is important since this enables us to focus on the stochastic discount factor in considering the determinants of asset prices (see, for example, Chochrane, 1996). As a significant foundation for many asset pricing models, the traditional version of consumption-based capital asset pricing model (CCAPM) is also important.

From the above viewpoints, we consider that it is worthwhile to revisit the classical CCAPM by using the GMM approach. Based on this motivation, this paper attempts to re-examine the traditional CCAPM by extending US monthly sample periods and by applying the GMM methodology conducted in Hansen and Singleton (1982).

Our investigations that cover the recent US data reveal the following facts. First, 1) in the cases of the CCAPM with consumption for nondurable goods and the CCAPM with consumption for nondurable goods and services, their discount rate parameters almost always take similar values that are slightly less than one. Second, 2) their risk aversion parameters more stably take small minus values in the CCAPM with consumption for nondurable goods than in the CCAPM with consumption for nondurable goods and services. Third, 3) in our empirical explorations, all estimated CCAPMs with two sorts of consumption are not rejected by the $J$-tests.

After this introduction, Section 2 briefly reviews the related existing literature and Section 3 explains our data and methodology that we employ in our tests for the US. Section 4 then describes the estimation results of our asset pricing models and finally, Section 5 summarizes the paper.

\section{Literature Review}

This section concisely reviews existing studies related with consumption-based asset pricing. In recent years, researchers interested in consumption-based asset pricing models pay attention to asset pricing models with recursive preferences, typically shown in such a study as Epstein and Zin (1989). In connection with this study, Vissing-Jørgensen and Attanasio (2003) suggested that considering the stockholders' consumption growth and asset returns was indeed helpful for yielding plausible values of the elasticity of intertemporal substitution (EIS) and for explaining the equity premium puzzle.

Moreover, an interesting study by Santos and Veronesi (2006) attempted to extend the standard consumption-based asset pricing model. In their model, the source of consumption was assumed to be, in particular, labor income and they empirically tested their model with actual data as well. Further, Menzly et al. (2004) suggested a consumption-based asset pricing model with habit formation and their proposed model also included the time-varying risk aversion.

From the methodological viewpoint, as we already stated, the GMM approach was proposed by such studies as those by Hansen (1982) and Hansen and Singleton (1982) to evaluate asset pricing models. After these studies, GMM has been highly popular for testing asset pricing 


\section{Macrothink}

Issues in Social Science

ISSN 2329-521X 2016, Vol. 4, No. 1

models. For example, Cochrane (1996) performed cross-sectional tests of multiple asset pricing models by combining the stochastic discount factor approach with GMM methodology. Further, Jagannathan and Wang (1996) empirically tested the conditional capital asset pricing models also by using GMM.

Moreover, an interesting study by Hansen et al. (2008) suggested that the cash flow variation and the consumption growth rate variation were important for asset valuation and they formalized and examined the long-run contribution to the value of the stochastic components of cash flows and discount factors. Using actual data, they also quantified the importance of macroeconomic risk in asset pricing.

Panel A. Consumption for nondurable goods

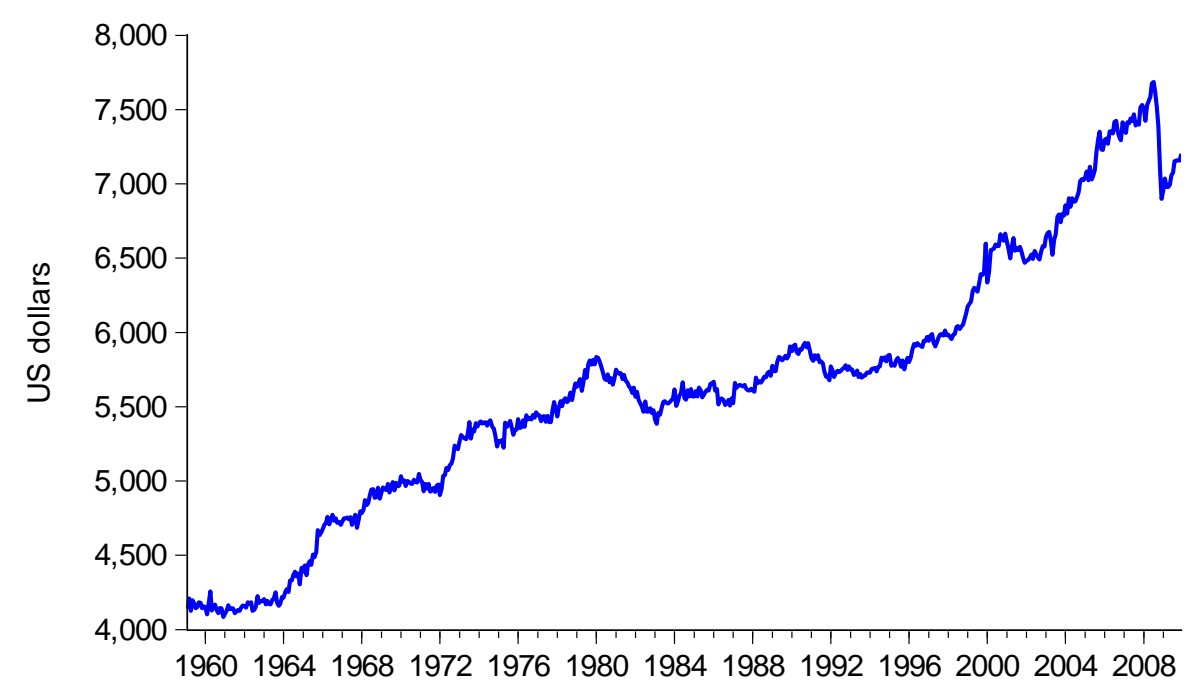

Panel B. Consumption for nondurable goods and services

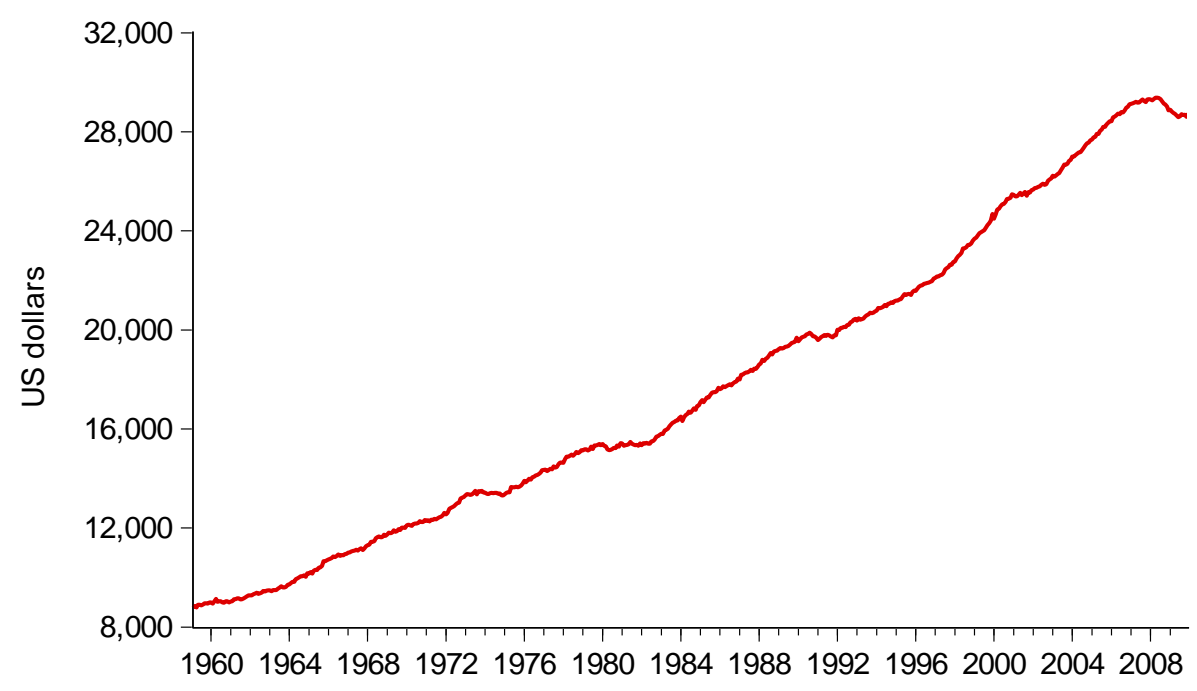

Figure 1. Trends of Per Capita Real Personal Consumption Expenditures in the US. 
Table 1. Descriptive statistics for real stock market returns and real consumption in the US: For the full sample period and three sub-sample periods

\begin{tabular}{|c|c|c|c|}
\hline \multicolumn{4}{|c|}{ Panel A. Statistics for the period from February 1959 to December 2009} \\
\hline & VWR & ND & NDS \\
\hline Mean & 1.0057 & 5630.3945 & 17803.9778 \\
\hline Maximum & 1.1589 & 7686.6118 & 29380.8496 \\
\hline Minimum & 0.7703 & 4084.8268 & 8777.9915 \\
\hline Standard deviation & 0.0447 & 866.4898 & 6197.8037 \\
\hline Skewness & -0.5340 & 0.2318 & 0.3530 \\
\hline Excess kurtosis & 1.8742 & -0.2796 & -1.0403 \\
\hline \multicolumn{4}{|c|}{ Panel B. Statistics for the period from February 1959 to December 1978} \\
\hline & VWR & ND & NDS \\
\hline Mean & 1.0030 & 4822.6642 & 11665.3346 \\
\hline Maximum & 1.1589 & 5656.0585 & 15140.1583 \\
\hline Minimum & 0.8700 & 4084.8268 & 8777.9915 \\
\hline Standard deviation & 0.0429 & 490.1623 & 1906.9826 \\
\hline Skewness & -0.0960 & -0.1370 & 0.0560 \\
\hline Excess kurtosis & 1.1490 & -1.3974 & -1.2838 \\
\hline \multicolumn{4}{|c|}{ Panel C. Statistics for the period from January 1975 to December 1994} \\
\hline & VWR & ND & NDS \\
\hline Mean & 1.0088 & 5632.3416 & 17207.5538 \\
\hline Maximum & 1.1362 & 5928.6829 & 21160.3982 \\
\hline Minimum & 0.7703 & 5223.5344 & 13360.8432 \\
\hline Standard deviation & 0.0449 & 152.0264 & 2326.4561 \\
\hline Skewness & -0.5690 & -0.2594 & 0.1151 \\
\hline Excess kurtosis & 3.3569 & -0.5805 & -1.3914 \\
\hline \multicolumn{4}{|c|}{ Panel D. Statistics for the period from January 1990 to December 2009} \\
\hline & VWR & ND & NDS \\
\hline Mean & 1.0059 & 6431.8368 & 24413.7949 \\
\hline Maximum & 1.1097 & 7686.6118 & 29380.8496 \\
\hline Minimum & 0.8340 & 5678.5123 & 19541.5386 \\
\hline Standard deviation & 0.0446 & 611.0340 & 3350.3895 \\
\hline Skewness & -0.6905 & 0.4041 & 0.0512 \\
\hline Excess kurtosis & 1.1108 & -1.2381 & -1.4656 \\
\hline
\end{tabular}

Notes: In this table, VWR denotes the real value-weighted stock market return in the US, ND means per capita real PCEs for nondurable goods in the US, and NDS denotes per capita real PCEs for nondurable goods and services in the US. Excess kurtosis in this table means the kurtosis value over three. 


\section{Data and Testing Methodology}

This study uses the data of stock market return, consumption, and a price deflator; and the latter two are seasonally adjusted data. More concretely, VWR denotes the real value-weighted stock market return in the US, ND means the US per capita real personal consumption expenditures (PCEs) for nondurable goods, and NDS denotes the US per capita real PCEs for nondurable goods and services. We deflated nominal values of the stock return and two kinds of PCEs by the deflator of total PCEs. The time-series trends of ND and NDS are shown in Figure 1. In addition, the descriptive statistics studied in this paper are shown in Table 1. We use three sub-sample periods with a full sample period. Our full sample period is from February 1959 to December 2009, the first sub-sample period is from February 1959 to December 1978, the second sub-sample period is from January 1975 to December 1994, and the last sub-sample period is from January 1990 to December 2009.

Using the above deflated data, following Hansen and Singleton's (1982) specification (1), we re-examine the traditional CAPM in the US by using the extended data.

$$
E_{t} h\left(\mathbf{x}_{\mathbf{t}+\mathbf{1}}, \mathbf{b}_{\mathbf{0}}\right)=E_{t}\left[\beta\left(x_{2 t+1}\right)^{\alpha} x_{1 t+1}-1\right]=0
$$

In the above equation, $h$ includes the parameter vector $\mathbf{b}_{\mathbf{0}}$ and the variable vector $\mathbf{x}_{\mathbf{t}+\mathbf{1}}$. Further, $\beta$ is the discount rate; $\alpha$ is the risk aversion parameter; $x_{2 t+1}$ means the growth of consumption (ND or NDS); and $x_{1+1}$ means the real market return. We estimate CCAPMs by using ND and NDS with GMM and in estimations, following Hansen and Singleton (1982), lag variables of VWR and consumption growth of ND or NDS are used as instrument variables.

Table 2. Estimation results of CCAPM with consumption for nondurable goods

Panel A. Results for the period from February 1959 to December 2009

\begin{tabular}{|c|c|c|c|c|c|c|}
\hline Cons. & Return & NLAG & $\beta$ & $p$-value & $\alpha$ & $p$-value \\
\hline ND & VWR & 1 & $0.9946^{* *}$ & 0.0000 & -1.4773 & 0.0869 \\
\hline \multicolumn{7}{|c|}{ Results of the $J$-test } \\
\hline$\chi^{2}$ & & & DF & & $p$-value & \\
\hline 2.6882 & & & 1 & & 0.1011 & \\
\hline Cons. & Return & NLAG & $\beta$ & $p$-value & $\alpha$ & $p$-value \\
\hline ND & VWR & 2 & $0.9944 * *$ & 0.0000 & -0.9909 & 0.2083 \\
\hline \multicolumn{7}{|c|}{ Results of the $J$-test } \\
\hline$\chi^{2}$ & & & $\mathrm{DF}$ & & $p$-value & \\
\hline 5.7545 & & & 3 & & 0.1242 & \\
\hline Cons. & Return & NLAG & $\beta$ & $p$-value & $\alpha$ & $p$-value \\
\hline ND & VWR & 4 & $0.9944 * *$ & 0.0000 & -1.1603 & 0.1304 \\
\hline \multicolumn{7}{|c|}{ Results of the $J$-test } \\
\hline$\chi^{2}$ & & & $\mathrm{DF}$ & & $p$-value & \\
\hline 7.6900 & & & 7 & & 0.3607 & \\
\hline
\end{tabular}




\begin{tabular}{lllllll}
\hline Cons. & Return & NLAG & $\beta$ & $p$-value & $\alpha$ & $p$-value \\
\hline ND & VWR & 6 & $0.9942 * *$ & 0.0000 & -1.2175 & 0.1091 \\
\hline \multicolumn{7}{c}{ Results of the $J$-test } \\
\hline$\chi^{2}$ & DF & $p$-value \\
\hline 12.2330 & & 11 & 0.3464 & \\
\hline
\end{tabular}

Panel B. Results for the period from February 1959 to December 1978

\begin{tabular}{lllllll}
\hline Cons. & Return & NLAG & $\beta$ & $p$-value & $\alpha$ & $p$-value \\
\hline ND & VWR & 1 & $0.9976^{* *}$ & 0.0000 & -1.5852 & 0.0536 \\
\hline
\end{tabular}

Results of the $J$-test

\begin{tabular}{lllllll}
\hline$\chi^{2}$ & \multicolumn{3}{c}{ DF } & \multicolumn{3}{c}{$p$-value } \\
\hline 1.7067 & & 1 & 0.1914 & \\
\hline Cons. & Return & NLAG & $\beta$ & $p$-value & $\alpha$ & $p$-value \\
\hline ND & VWR & 2 & $0.9975^{* *}$ & 0.0000 & -0.9068 & 0.2091 \\
\hline
\end{tabular}

Results of the $J$-test

\begin{tabular}{lllllll}
\hline$\chi^{2}$ & \multicolumn{3}{c}{ DF } & \multicolumn{3}{c}{$p$-value } \\
\hline 6.8719 & & 3 & 0.0761 & \\
\hline Cons. & Return & NLAG & $\beta$ & $p$-value & $\alpha$ & $p$-value \\
\hline ND & VWR & 4 & $0.9980^{* *}$ & 0.0000 & -0.6340 & 0.3509 \\
\hline
\end{tabular}

Results of the $J$-test

\begin{tabular}{lllllll}
\hline$\chi^{2}$ & \multicolumn{3}{l}{ DF } & & $p$-value \\
\hline 10.7907 & & 7 & 0.1480 & \\
\hline Cons. & Return & NLAG & $\beta$ & $p$-value & $\alpha$ & $p$-value \\
\hline ND & VWR & 6 & $0.9982^{* *}$ & 0.0000 & -0.8383 & 0.1842 \\
\hline
\end{tabular}

Results of the $J$-test

\begin{tabular}{lll}
\hline$\chi^{2}$ & DF & $p$-value \\
\hline 18.1214 & 11 & 0.0788
\end{tabular}

Panel C. Results for the period from January 1975 to December 1994

\begin{tabular}{lllllll}
\hline Cons. & Return & NLAG & $\beta$ & $p$-value & $\alpha$ & $p$-value \\
\hline ND & VWR & 1 & $0.9920 * *$ & 0.0000 & -0.9311 & 0.4056
\end{tabular}

Results of the $J$-test

\begin{tabular}{lllllll}
\hline$\chi^{2}$ & \multicolumn{3}{c}{ DF } & $p$-value \\
\hline 0.1620 & \multicolumn{7}{c}{1} & 0.6873 & \\
\hline Cons. & Return & NLAG & $\beta$ & $p$-value & $\alpha$ & $p$-value \\
\hline ND & VWR & 2 & $0.9916^{* *}$ & 0.0000 & -1.3632 & 0.2127 \\
\hline \multicolumn{7}{c}{ Results of the $J$-test } \\
\hline$\chi^{2}$ & \multicolumn{7}{c}{ DF } & $p$-value \\
\hline
\end{tabular}




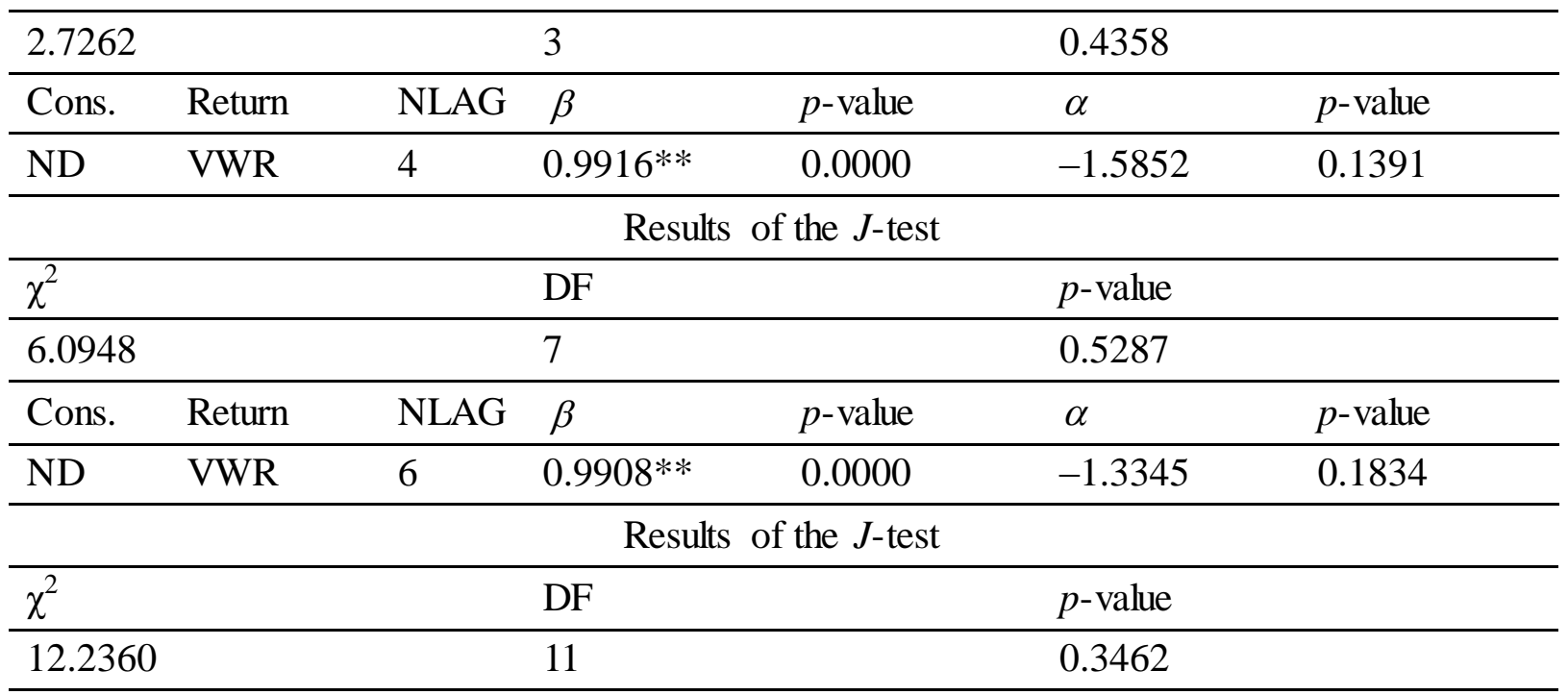

Panel D. Results for the period from January 1990 to December 2009

\begin{tabular}{lllllll}
\hline Cons. & Return & NLAG & $\beta$ & $p$-value & $\alpha$ & $p$-value \\
\hline ND & VWR & 1 & $0.9961^{* *}$ & 0.0000 & -3.3489 & 0.1930 \\
\hline
\end{tabular}

Results of the $J$-test

\begin{tabular}{|c|c|c|c|c|c|c|}
\hline$\chi^{2}$ & & & DF & & $p$-value & \\
\hline 0.1446 & & & 1 & & 0.7038 & \\
\hline Cons. & Return & NLAG & $\beta$ & $p$-value & $\alpha$ & $p$-value \\
\hline ND & VWR & 2 & $0.9944 * *$ & 0.0000 & -1.4203 & 0.3950 \\
\hline \multicolumn{7}{|c|}{ Results of the $J$-test } \\
\hline$\chi^{2}$ & & & DF & & $p$-value & \\
\hline 1.5257 & & & 3 & & 0.6764 & \\
\hline Cons. & Return & NLAG & $\beta$ & $p$-value & $\alpha$ & $p$-value \\
\hline ND & VWR & 4 & $0.9942 * *$ & 0.0000 & -1.0734 & 0.4393 \\
\hline
\end{tabular}

Results of the $J$-test

\begin{tabular}{|c|c|c|c|c|c|c|}
\hline$\chi^{2}$ & & & DF & & $p$-value & \\
\hline 3.0137 & & & 7 & & 0.8837 & \\
\hline Cons. & Return & NLAG & $\beta$ & $p$-value & $\alpha$ & $p$-value \\
\hline ND & VWR & 6 & $0.9938 * *$ & 0.0000 & -0.9996 & 0.4428 \\
\hline \multicolumn{7}{|c|}{ Results of the $J$-test } \\
\hline$\chi^{2}$ & & & DF & & $p$-value & \\
\hline 3.2526 & & & 11 & & 0.9869 & \\
\hline
\end{tabular}

Notes: VWR is the US real value-weighted stock market return, ND is per capita real PCEs for nondurable goods in the US, and Cons. means consumption. NLAG is the lag of instrument variables, $\chi^{2}$ denotes the chi-square statistic, and DF means the degree of freedom. $* *$ and $*$ mean the statistical significance at the $1 \%$ and $5 \%$ levels, respectively. 


\section{Macrothink}

Issues in Social Science

ISSN 2329-521X

2016, Vol. 4, No. 1

Table 3. Estimation results of CCAPM with consumption for nondurable goods and services

Panel A. Results for the period from February 1959 to December 2009

\begin{tabular}{|c|c|c|c|c|c|c|}
\hline Cons. & Return & NLAG & $\beta$ & $p$-value & $\alpha$ & $p$-value \\
\hline NDS & VWR & 1 & $0.9948 * *$ & 0.0000 & -0.8606 & 0.6543 \\
\hline \multicolumn{7}{|c|}{ Results of the $J$-test } \\
\hline$\chi^{2}$ & & & $\mathrm{DF}$ & & $p$-value & \\
\hline 3.4536 & & & 1 & & 0.0631 & \\
\hline Cons. & Return & NLAG & $\beta$ & $p$-value & $\alpha$ & $p$-value \\
\hline NDS & VWR & 2 & $0.9940 * *$ & 0.0000 & -0.4171 & 0.8288 \\
\hline \multicolumn{7}{|c|}{ Results of the $J$-test } \\
\hline$\chi^{2}$ & & & DF & & $p$-value & \\
\hline 6.4327 & & & 3 & & 0.0924 & \\
\hline Cons. & Return & NLAG & $\beta$ & $p$-value & $\alpha$ & $p$-value \\
\hline NDS & VWR & 4 & $0.9932 * *$ & 0.0000 & -0.0769 & 0.9557 \\
\hline \multicolumn{7}{|c|}{ Results of the $J$-test } \\
\hline$\chi^{2}$ & & & $\mathrm{DF}$ & & $p$-value & \\
\hline 7.9449 & & & 7 & & 0.3375 & \\
\hline Cons. & Return & NLAG & $\beta$ & $p$-value & $\alpha$ & $p$-value \\
\hline NDS & VWR & 6 & $0.9929 * *$ & 0.0000 & -0.0502 & 0.9700 \\
\hline \multicolumn{7}{|c|}{ Results of the $J$-test } \\
\hline$\chi^{2}$ & & & $\mathrm{DF}$ & & $p$-value & \\
\hline 12.1544 & & & 11 & & 0.3521 & \\
\hline
\end{tabular}

Panel B. Results for the period from February 1959 to December 1978

\begin{tabular}{lllllll}
\hline Cons. & Return & NLAG & $\beta$ & $p$-value & $\alpha$ & $p$-value \\
\hline NDS & VWR & 1 & $0.9991^{* *}$ & 0.0000 & -1.4270 & 0.5130 \\
\hline
\end{tabular}

Results of the $J$-test

\begin{tabular}{|c|c|c|c|c|c|c|}
\hline$\chi^{2}$ & & & DF & & $p$-value & \\
\hline 1.3540 & & & 1 & & 0.2446 & \\
\hline Cons. & Return & NLAG & $\beta$ & $p$-value & $\alpha$ & $p$-value \\
\hline NDS & VWR & 2 & $0.9955^{* *}$ & 0.0000 & 0.4755 & 0.8063 \\
\hline \multicolumn{7}{|c|}{ Results of the $J$-test } \\
\hline$\chi^{2}$ & & & $\mathrm{DF}$ & & $p$-value & \\
\hline 4.0130 & & & 3 & & 0.2601 & \\
\hline Cons. & Return & NLAG & $\beta$ & $p$-value & $\alpha$ & $p$-value \\
\hline NDS & VWR & 4 & $0.9955 * *$ & 0.0000 & 0.4053 & 0.8062 \\
\hline
\end{tabular}

Results of the $J$-test 


\begin{tabular}{|c|c|c|c|c|c|c|}
\hline$\chi^{2}$ & & & DF & & $p$-value & \\
\hline 5.6960 & & & 7 & & 0.5757 & \\
\hline Cons. & Return & NLAG & $\beta$ & $p$-value & $\alpha$ & $p$-value \\
\hline NDS & VWR & 6 & $0.9975 * *$ & 0.0000 & -0.3223 & 0.8372 \\
\hline \multicolumn{7}{|c|}{ Results of the $J$-test } \\
\hline$\chi^{2}$ & & & $\mathrm{DF}$ & & $p$-value & \\
\hline 9.9509 & & & 11 & & 0.5348 & \\
\hline
\end{tabular}

Panel C. Results for the period from January 1975 to December 1994

\begin{tabular}{|c|c|c|c|c|c|c|}
\hline Cons. & Return & NLAG & $\beta$ & $p$-value & $\alpha$ & $p$-value \\
\hline NDS & VWR & 1 & $0.9910 * *$ & 0.0000 & 0.1793 & 0.9437 \\
\hline \multicolumn{7}{|c|}{ Results of the $J$-test } \\
\hline$\chi^{2}$ & & & DF & & $p$-value & \\
\hline 0.4108 & & & 1 & & 0.5215 & \\
\hline Cons. & Return & NLAG & $\beta$ & $p$-value & $\alpha$ & $p$-value \\
\hline NDS & VWR & 2 & $0.9904 * *$ & 0.0000 & -0.400 & 0.9874 \\
\hline \multicolumn{7}{|c|}{ Results of the $J$-test } \\
\hline$\chi^{2}$ & & & DF & & $p$-value & \\
\hline 3.4710 & & & 3 & & 0.3245 & \\
\hline Cons. & Return & NLAG & $\beta$ & $p$-value & $\alpha$ & $p$-value \\
\hline NDS & VWR & 4 & $0.9939 * *$ & 0.0000 & -1.3723 & 0.4979 \\
\hline \multicolumn{7}{|c|}{ Results of the $J$-test } \\
\hline$\chi^{2}$ & & & $\mathrm{DF}$ & & $p$-value & \\
\hline 10.9577 & & & 7 & & 0.1405 & \\
\hline Cons. & Return & NLAG & $\beta$ & $p$-value & $\alpha$ & $p$-value \\
\hline NDS & VWR & 6 & $0.9969 * *$ & 0.0000 & -2.9921 & 0.1160 \\
\hline \multicolumn{7}{|c|}{ Results of the $J$-test } \\
\hline$\chi^{2}$ & & & DF & & $p$-value & \\
\hline 16.0265 & & & 11 & & 0.1402 & \\
\hline
\end{tabular}

Panel D. Results for the period from January 1990 to December 2009

\begin{tabular}{lllllll}
\hline Cons. & Return & NLAG & $\beta$ & $p$-value & $\alpha$ & $p$-value \\
\hline NDS & VWR & 1 & $1.0078^{* *}$ & 0.0000 & -9.4492 & 0.2775 \\
\hline \multicolumn{7}{c}{ Results of the $J$-test } \\
\hline$\chi^{2}$ & DF & $p$-value \\
\hline 1.1760 & & 1 & 0.2782 & \\
\hline Cons. & Return & NLAG & $\beta$ & $p$-value & $\alpha$ & $p$-value \\
\hline NDS & VWR & 2 & $0.9857^{* *}$ & 0.0000 & 4.0526 & 0.4947
\end{tabular}




\begin{tabular}{|c|c|c|c|c|c|c|}
\hline \multicolumn{7}{|c|}{ Results of the $J$-test } \\
\hline$\chi^{2}$ & & & $\mathrm{DF}$ & & $p$-value & \\
\hline 4.3473 & & & 3 & & 0.2263 & \\
\hline Cons. & Return & NLAG & $\beta$ & $p$-value & $\alpha$ & $p$-value \\
\hline NDS & VWR & 4 & $0.9915 * *$ & 0.0000 & 0.3314 & 0.9141 \\
\hline \multicolumn{7}{|c|}{ Results of the $J$-test } \\
\hline$\chi^{2}$ & & & $\mathrm{DF}$ & & $p$-value & \\
\hline 6.8448 & & & 7 & & 0.4452 & \\
\hline Cons. & Return & NLAG & $\beta$ & $p$-value & $\alpha$ & $p$-value \\
\hline NDS & VWR & 6 & $0.9926^{* * *}$ & 0.0000 & -0.0907 & 0.9761 \\
\hline \multicolumn{7}{|c|}{ Results of the $J$-test } \\
\hline$\chi^{2}$ & & & DF & & $p$-value & \\
\hline 8.4820 & & & 11 & & 0.6696 & \\
\hline
\end{tabular}

Notes: In this table, VWR is the US real value-weighted stock market return, NDS denotes per capita real PCEs for nondurable goods and services in the US, and Cons. means consumption. NLAG is the lag of instrument variables, $\chi^{2}$ denotes the chi-square statistic, and DF means the degree of freedom. $* *$ and $*$ mean the statistical significance at the $1 \%$ and $5 \%$ levels, respectively.

\section{Empirical Results}

This section documents our empirical results. Estimation results of the CCAPM with consumption for nondurable goods (ND) are shown in Table 2 and those of the CCAPM with consumption for nondurable goods and services (NDS) are exhibited in Table 3. In both tables, the lag of instrument variables is 1, 2, 4, or, 6 as in Hansen and Singleton (1982). In the case of the CCAPM with ND shown in Table 2, discount rate parameters always take similar values, which are slightly less than one; while risk aversion parameters stably take small minus values in general. Further, no estimated CCAPM with ND is rejected by the $J$-tests when judged by the $5 \%$ statistically significance level.

Next, in the case of the CCAPM with NDS exhibited in Table 3, discount rate parameters always take similar values, which are slightly less than one, except for the only one case in Panel D. As for risk aversion parameters, although some inconsistent parameter values are seen in Table 3, they generally take small minus values. Further, like the case of the CCAPM with ND, all estimated CCAPMs with NDS are not rejected by the $J$-tests when judged by the $5 \%$ statistically significance level.

\section{Conclusions}

This paper re-examined the traditional CCAPM by updating and extending US monthly samples. In our investigations, we followed the methodology of GMM with instrumental 
variables developed by Hansen and Singleton (1982). Our examinations derived the following facts. First, 1) in the cases of the CCAPM with consumption for nondurable goods and the CCAPM with consumption for nondurable goods and services, their discount rate parameters almost always took similar values that were slightly less than one. Second, 2) their risk aversion parameters more stably took reasonable small minus values in the CCAPM with consumption for nondurable goods than in the CCAPM with consumption for nondurable goods and services. Third, 3) all estimated CCAPMs with two kinds of consumption were not rejected by the $J$-tests in our empirical examinations.

In asset pricing research, the methodology by Hansen and Singleton (1982) is important and the traditional CCAPM model as studied in this paper is also important. We consider that the findings derived from our reexaminations are highly informative for future research since we largely updated the US samples compared with those in Hansen and Singleton (1982). Nevertheless, since new researches are also emerging (e.g., Park, 2014; Kwan et al., 2015; Boons, 2016), further investigation by using other data and other models is one of our future tasks.

\section{Acknowledgement}

The author is particularly grateful to the repeated kind invitation from the journal to write to this journal. The author also appreciates the Chuo University Grant for Special Research for their generous financial assistance to this research. Moreover, I thank the anonymous referees for their comments on this paper, and I particularly thank the Editor, Lily Mayer, for the kind invitation to this journal. Finally, I deeply thank all Editors of this journal for their kindness to this paper.

\section{References}

Boons, M. (2016). State variables, macroeconomic activity, and the cross section of individual stocks. Journal of Financial Economics, 119, 489-511. http://dx.doi.org/10.1016/j.jfineco.2015.05.010

Cochrane, J. H. (1996). A cross-sectional test of an investment-base asset pricing model. Journal of Political Economy, 104, 572-621.

Epstein, L. G, \& Zin, S. E. (1989). Substitution, risk aversion, and the temporal behavior of consumption and asset returns: A theoretical framework. Econometrica, 57, 937-969. http://dx.doi.org/10.2307/1913778

Hansen, L. P. (1982). Large sample properties of generalized method of moments estimators. Econometrica, 50, 1029-1054. http://dx.doi.org/10.2307/1912775

Hansen, L. P., \& Singleton, K. J. (1982). Generalized instrumental variables estimation of nonlinear rational expectations models. Econometrica, 50, 1269-1286. http://dx.doi.org/ $10.2307 / 1911873$

Hansen, L. P., Heaton, J., \& Li, N. (2008). Consumption strikes back? Measuring long-run risk. Journal of Political Economy, 116, 260-302. http $/ /$ dx.doi.org/10.1086/588200 


\section{Macrothink}

Jagannathan, R., \& Wang, Z. (1996). The conditional CAPM and the cross-section of $\begin{array}{lllll}\text { expected } \text { returns. Journal } & \text { 3-53. }\end{array}$ http://dx.doi.org/10.1111/j.1540-6261.1996.tb05201.x

Kwan, Y. K., Leung, C. K. Y., \& Dong, J. (2015). Comparing consumption-based asset pricing models: The case of an Asian city. Journal of Housing Economics, 28, 18-41. http://dx.doi.org/10.1016/j.jhe.2014.12.001

Menzly, L., Santos, T., \& Veronesi, P. (2004). Understanding predictability. Journal of Political Economy, 112, 1-47. http://dx.doi.org/10.1086/379934

Park, B. J. (2014). Time-varying, heterogeneous risk aversion and dynamics of as set prices among boundedly rational agents. Journal of Banking \& Finance, 43, 150-159. http://dx.doi.org/10.1016/j.jbankfin.2014.03.009

Santos, T., \& Veronesi, P. (2006). Labor income and predictable stock returns. Review of Financial Studies, 19, 1-44. http//dx.doi.org/10.1093/rfs/hhj006

Vissing-Jørgensen, A., \& Attanasio, O. P. (2003). Stock-market participation, intertemporal substitution and risk-aversion. American Economic Review, 93, 383-391. http://dx.doi.org/10.1257/000282803321947399

\section{Copyright Disclaimer}

Copyright for this article is retained by the author(s), with first publication rights granted to the journal.

This is an open-access article distributed under the terms and conditions of the Creative Commons Attribution license (http://creativecommons.org/licenses/by/3.0/). 